\title{
Comparison of frequencies of the notes between the ranges of $B 3$ to $D 5$ with human voice: $A$ software design approach in MATLAB and its availability in music skill tests
}

\author{
Ali AYHAN \\ Faculty of Education, Department of Fine Arts Education, Music Education Program, Inonu University, Malatya, Turkey.
}

Received 10 August, 2014; Accepted 29 September, 2014

\begin{abstract}
In this study, a program was developed that allows one to listen to sounds existing in computer, with the algorithms based on signal processing logic which is available via Fourier Transform in MATLAB program. The heard sound is recorded when it is repeated by human voice, and its frequency is compared to the frequencies of existing sounds in the computer to obtain measurement results. The first version of the program to be developed used piano notes in the range of B3-D5. The program generates measurement results in graphic form, corresponding to notes sung. In addition, the frequency results are shown in the information display. One of the main objectives of the study is to develop a measurement system that could be applied in music special aptitude tests. In music aptitude tests, in the questions about sounds repeating, the jury's perception is altered by factors such as fatigue, and candidates' measurement results are affected by this problem. This program seeks to eliminate this negative effect in the measurements results of the aptitude test. The first version of the program developed in this study was tested on 10 people. The Pearson correlation analysis was performed with the aim of examining the relationship between achievement levels of students in one voice field and fixed frequency values. The result of this analysis was a meaningful, positive and highlevel relationship between fixed values of 16 notes frequencies in the range of B3-D5 and singing values of the students regarding these 16 notes.
\end{abstract}

Key words: Music education, music aptitude test, MATLAB, Fourier transform, aptitude test program.

\section{INTRODUCTION}

Music is an art which has an important place in society. Performance of music is observed in different dimensions in human life. Those who wish to pursue the art of music must possess a certain degree of musical ability. Today, whether at a professional or amateur level, people begin their musical training only once their level of aptitude has been determined. To this end, students' skills and aptitudes in terms of music are measured and assessed in musical aptitude tests. In the field of measurement and evaluation, scores often consist of hearing, writing, and

\section{E-mail: a li.ayhan@inonu.edu.tr. Tel: +905442282082.}

Authors agree that this article rema in pemanently open access under the terms of the $\underline{\text { Creative Commons }}$ Attribution License 4.0 Intemational Lic ense 
playing music (Sağer et al., 2014, 1).

The programs take the candidates to the exams individually and as groups by determining levels according to the set of questions identified (Sağer et al., 2014, 36).

Measurement of musical talent is a concept based on sensation. How does this seemingly arbitrary concept work? We can answer this based on what we know about the physical structure of the sounds and sound perception mechanism of our hearing system. A certain sound, that is closely connected to the brain and stored in its memory files, will evoke aural memories (Zeren, 2008: 1). The sounds stored in the mind at birth, and even before birth in the womb, create various images and concept maps in our brains. Every aspect of the art of music is linked to the special meanings and concepts generated by distinguishing among these sound images. The current preferred explanation for these concepts is a physical one. The third step of musical event is the analysis of the sound waves passing through hearing organs (ear and brain); in other words, it is the perception and evaluation of sound. A major part of this step includes the physical phenomenon. Therefore, it is related physically and is explained physically (Zeren, 2003:5).

In physical terms, human beings have a limited ability to perceive sounds. The average human ear can detect sounds in the range of 20 to $20,000 \mathrm{~Hz}$. However, people's perception of sound can be easily altered by environmental factors, among others. The main objective of this study is concerned with this situation. How can the errors based on perception in the results of musical aptitude tests be removed?

There are several tests used to measure musical behaviours, abilities and skill levels. There are a variety of approaches for the classification of these tests. Boyle and Radocy (1987) have divided the music tests into four main categories:

\section{1-Musical Aptitude Tests}

2-Musical Achievement Tests

3-Musical Performance Tests

4-Musical Attitude and Other Emotional Variables Tests (Sağer et al., 2013: 543)".

This study attempts to develop a program based on musical aptitude tests. It is not uncommon for members of the jury who evaluate the musical aptitude of the candidates to have some problems in evaluating the sounds produced by students, particularly as they become fatigued. This results in errors in measurement results which will affect the results of the exam andmore importantly - the prospects of the candidates.

The main principle in musical aptitude tests is to eliminate this kind of measurement errors. However, much attention is given to this kind of problem; and errors related with measurement are nearly impossible to eradicate. In this vein, to what extent could computers be used to eliminate or minimize this kind of problem? The technical information we need to carry out such a study with current computer technology is given briefly bwlow.

Moorer talks about the second aim in signal processing in his work titled, signal processing aspects of computer music. The results obtained in the synthesis which we call analysis based synthesis are used for forging the synthesis by developing them. Also, recent developments in this field have made this concept more appropriate than thought before. Thus, these developments promise that this field will be rich for future studies (Moorer, 1977: 4).

The rich study field projected in 1977 is now at our fingertips with today's technological facilities. That is to say, techniques in the field of sound synthesis have undergone striking developments.

Today, the most common sound synthesis is a computer and speakers that are controlled by it. From the simplest to the most complex of voice synthesis can be generated in this environment. Such a broad sound space is available to musicians that it provides a bridge between imagined and heard (Arapgirlioğlu, 2003: 161).

On the basis of some of studies, sine curve models are often used for signal representation of music or speech, and analysis or transformation. The most important step for the emergence of the sine model is the estimation of the sine phases obtained from peaks which are acquired via approximate amplitude, frequency values and Discrete Fourier Transform (DFT). Estimates are quite easy when the signals are fixed, and Quick Fourier Transform Estimator (QIFFT) is used as a standard for this process. QIFFT uses a second polynomial model that consists of the maximum value of the spectral hit (peak) and amplitude of the peak hit and logarithm of the unwrapped phase (Röbel, 2003: 68).

If we continue to go over these kind of studies, we have Naranjo and Koffi's study named "geometric image modelling of musical object" which emphasizes that, after the revolutions in graphic systems, drawing two-dimensional graphics of musical phrases or three-dimensional topographic maps is currently possible. When the article is investigated, it is understood that these drawings are made with Discrete Fourier Transform (DFT) (Naranjo and Koffi, 1988: 70).

In Alm and Walker (2002)'s study, time-frequency analysis of musical instruments, there is detailed information on the principles and mathematical equations the Fourier Transform works with. The authors mentioned that Fourier series are classical mathematical theory which explains musical notes, and which formulas and methods are used in detail (Alm and Walker, 2002: 459459).

Studies about music education technology have gained momentum in the last twenty years. When these studies 
are assessed in terms of software programs, there are some headings below about used actively software related with music education and whose objectives are used.

1. Ear training programs prepared with various sound libraries.

2. Notation programs

3. Virtual instrument programs

4. Instrument tuning programs

5. Studio recording programs

Koç, who suggests that by assessing the general features of the computer-aided musical software it is possible to categorize these programs in groups, has classified the important field headings such as Music Education Programs (Instructional Software), practicebased programs (Practice/ Accompaniment Software), notation programs (Notation/Scoring Software), and "Sequencer" system (Sequencing Software); that is desktop system used for making by creating a sort of motion (Koç, 2004:2).

Whichever program is used, they all have a common basis of computer code. We have the opportunity to make the computers operate precisely how we want with interfaces prepared using appropriate codes. Some very effective software created with computer codes is being used actively in music education today.

Başuğur stresses that the onset of interactive software in education led to discussions and investigations about the applicability, positive and negative sides, and benefitcost aspects of these programs; however, with the good results obtained from the experiments, this new method understanding is no longer controversial. He mentions that interactive software is being used in world's most respectable music institutions, despite opposition which suggests that these programs eliminate emotion and spontaneity and limit creativity. The advantages of these software for lesson preparation or compensating for the personal shortcomings are significant (Başuğur, 2009: 2).

Bauer et al. shed light on the situation of the music education and training in 1984 in their study. They talk about the researches and investigations which stress that, in those years, to be able to realize an effective music education, it was necessary to use the technological facilities effectively. The authors specifically talk about the fact that, even in those years, there was a tendency to assess and underline the necessity of the software and hardware resources (Bauer et al., 2003, 290). If we can make proper use of the technological facilities today, we can improve the quality of music education via technology projected.

One of the programs designed for the development of musical talent is "Sibelius Auralia". In addition to providing rhythmic, melodic and range exercises this music education software aims to improve perception of variation or repetition while making the listener hears with a musical ear. For this purpose, different test groups were created in the program. Through this program, musical ear could be improved in preparation for music aptitude tests.

AMMA or "Advanced Measures of Music Audition" is another music education software. In this program, which has different versions for various age and education levels, there is a system that is used with the aim of measuring the reasoning of the performing music by asking questions already existing in sound library in different ways. This program could potentially be a highly beneficial source or preparation for music aptitude tests. While these programs provide a helpful source or preparation for prospective candidates, what about software that will increase the reliability of measuring results in different question types? Is it possible to design such a program? What positive contributions could eliminate the measuring problems encountered in music talent exams, comprehensively identifying the talent of the candidates? To design programs that will answer these questions, we must look for programs which facilitate software development. MATLAB is one of them. Algorithms have been designed to be used in the program as signal processing functions, and which can be implemented in MATLAB software.

The basic working units in MATLAB are matrices. The elements of the matrices may be real, complex, or symbolic. The matrices may be column vectors, row vectors, or scalars. For our purposes, almost all units are vectors or scalars (Su, 2002:7).

The widely used signal processing package Matlab® makes the division by $\mathrm{N}$ in the inverse transform, giving a version more closely related to the Fourier transform pair of (1) and (2). However, the sum will then only represent the integral (over a finite length time signal) when the forward transform is multiplied by delta $(t)$, the time interval between samples (Havelock et al., 2008:83).

It is possible to compare the human sounds with the recorded ones in the computer using the properties of MATLAB. Rumsey, in his study in 2004, mentions the MATLAB program as a popular program whose interfaces can be used in signal processing (Rumsey, 2004: 235). By using the signal processing and command lines in FFT functions of MATLAB editor, a musical aptitude test has been developed in this study. The basis of this application is to compare the frequencies of the human voice in single sounds. Further details about this program can be found in the findings and interpretations of this study.

\section{The objective of the study}

It is aimed that music software be prepared in computer media will contribute to the elimination of the measuring 
problems encountered during music talent tests, thereby fully identifying the talents of the candidates as part of a highly sensitive measuring program.

\section{The importance of the research}

The software that is prepared via this study will be a step towards eliminating human errors in scoring music aptitude tests, points of measurement and assessment which have a crucial position in educational plans. Additionally, in tests where the work expended in these exams is taken into consideration, the instalment of a multifaceted system in the exam environment will prevent a substantial loss of time and labour. Candidates are largely unable to perform satisfactorily, as they keenly feel the time problem and are made nervous as a result; this impediment is particularly apparent in the question types dealt with by this program. In music aptitude tests where there are long queues, candidates cannot perform to their actual potential in a measurement which is taken hurriedly. By creating a full music talent test, derived from the first version of this program, and setting it up to 5 on 6 computers, multiple candidates could be tested at the same time. Organized this way, the candidates would not get nervous due to long waits. Thus, the negative impact of time and overexcitement is eliminated when considered in terms of the results to be obtained from these studies; therefore, these contribute to the importance of the study.

\section{Premises}

In this study, it has been assumed that measurement problems in music aptitude tests could be eliminated via a new software that will measure frequencies, and this software can also be considered an application for music aptitude test consisting of codes written with the MATLAB program. In the first testing of this program-software the number of the subjects is 10 , all of whom have prior music education. It is assumed that this number is sufficient to test whether this frequency measuring software runs properly.

\section{Limitations}

In the first version of the program that has been generated, the sound range of the notes measured is limited to B3-D5. Candidates submitting to the musical aptitude test are generally questioned about notes from this range. For this reason, files containing B3-D5 range (created using piano sounds, and the sound library of the program Logic Pro X) were generated in wav format for use in the MATLAB editing program. It is possible to measure their frequencies with the functions in MATLAB and compare with the human voice.

\section{METHODOLOGY}

In this chapter is given information about the method that will be followed according to the aim of the research and sub-problems.

In this study, in MATLAB software, codes were written based on algorithms that will be used to analyse the items below.

1. Making people hear the sounds within the range of B3 and D5 in the audio library as they are played. To do this, by investigating the command lines in MATLAB, the related ones were used for the study. In this way, the necessary algorithms used for the running of the first version of the program were completed.

2. Whenever these sounds are played they are shown in the related part of the program interface by measuring its frequency. For this purpose, the MATLAB editor section was used to create the application interface.

3. Recording the sound heard through the microphone. The algorithm created with the command line with the save button during program execution using the computer's user's perception of his voice in wav format is provided.

4.By measuring the frequency of the sound recorded, and displaying it in the related part of the program interface. The frequency of the candidate's voice and the ones already existing in the computer are shown on the information display. This is achieved by developing the algorithm in the first section of the application and measuring the frequency of sound both in the computer and as it is sung by the candidate.

5. To name the recorded sounds, creating an 'add user' option. As this application has been designed for aptitude tests, recording candidates' information is important. For this purpose, a filing system has been created in the program. Candidates with doubts about their recordings can easily check their responses. In this way, the sounds candidates have sung are filed in the computer in wav format by writing the related information in the program.

6. Creating the graphics of already existing sounds in the program as well as the ones yet to be recorded. Drawing graphic features in the program enhance its capacity for analysis and detailed research. Drawing graphics of amplitude, magnitude, frequency and duration of playing are produced using various command lines for sounds which the program processes as they are played or recorded. In the following sections of the study the information about these graphics are included.

After this stage, the program has been tested on 10 different people, and the frequencies when they sang the notes between B3D5 were measured.

Only trained individuals were involved in the implementation of this experimental music training. Detailed information on the test results are in the findings and interpretations of this study.

\section{Research model}

This research is a trial in terms of developing a computer oriented program to measure and assess special aptitude exams. It is also a relational scanning model to assess the relationship between the points students produce through the program and its fixed frequency values.

\section{FINDINGS AND INTERPRETATION}

The interface of the program that was created using the 


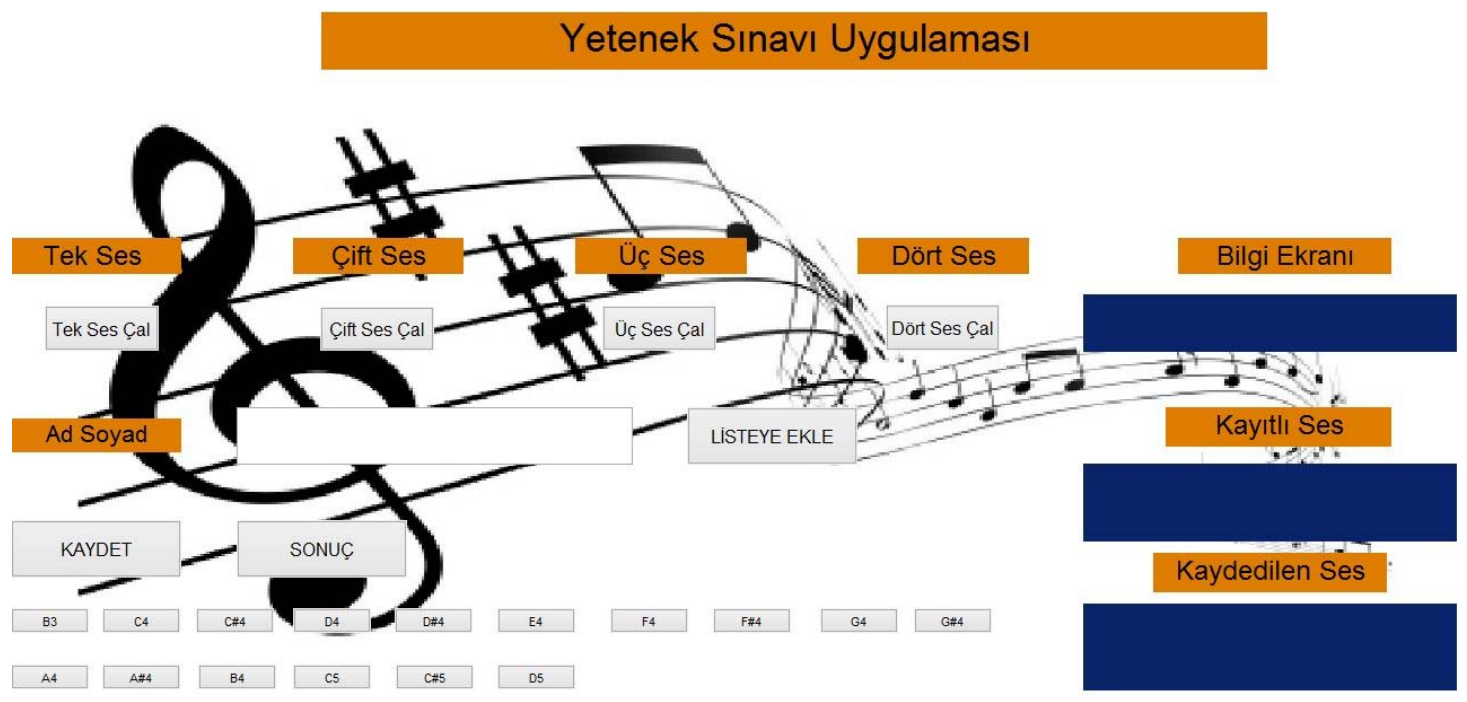

Figure 1. General overview of the program.

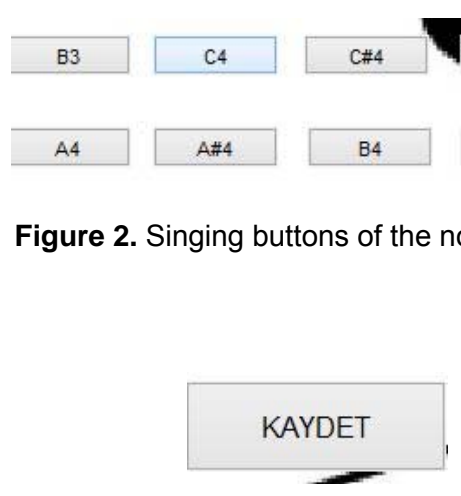

Figure 3. Save button

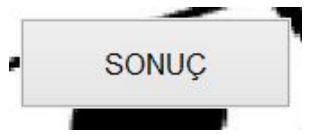

Figure 4. Results button.
MATLAB program codes is shown in Figure 1. As it is the first version of the program, the functions in the image such as 'play two sounds', 'play three sounds', 'play four sounds' have not been activated. In subsequent versions of the program, these functions will also be activated. For the time being, this section contains information about the core principles of the program and implementations on one voice.

The notes in the range between B3-D5 were converted to wav format using the piano sounds in Logic Pro, when clicking the buttons with their names in the interface that was created with MATLAB program (Figure 2).

The running principle of the buttons with which the notes are shown is generally provided by wavread and sound functions in the program.

To save the sound of the note as it is reproduced by the human voice the save button is pressed for five seconds. To make a voice recording, the program's voice recording feature with Save button in the interface is used (har=dsp.AudioRecorder;). Thus, audio recording is made available (Figure 3).

The frequency belonging to the recorded voice is measured by pressing the Result button. Results are displayed in the information screen in the interface of the program using the wavread and display functions in the related instruction line (Figure 4).

The "Add User" button has been designed to create identification information for the sounds whose frequencies will be measured in the interface of the program. By clicking on the empty button shown below and typing one's name, it is easily possible to perform this process. For example, after playing the note A4, if you want to record it after singing, click the 'save button.' A wav file appears on the desktop with the name which was written on "Add User" (Figure 5).

This is the section where instant information is 


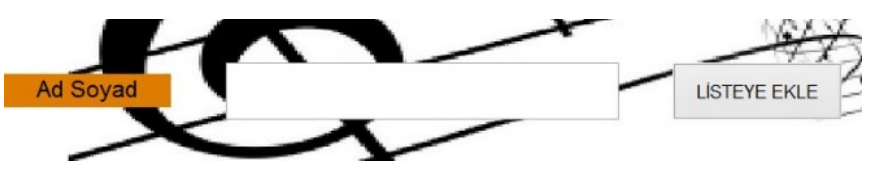

Figure 5. "Add User" Section.

\section{Bilgi Ekranı}

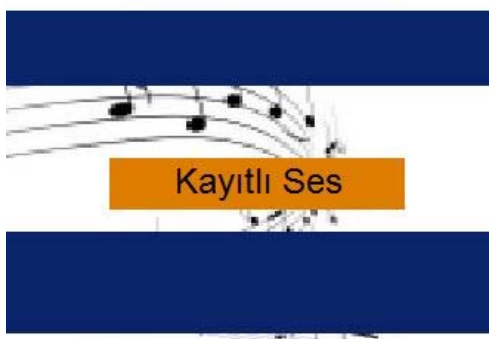

Kaydedilen Ses

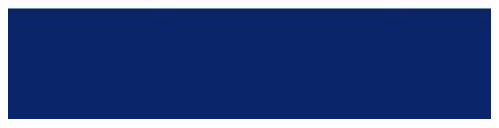

Figure 6. Information Screens.

Table 1. The frequencies of the notes in the range between B3-D5

\begin{tabular}{lc}
\hline Note & Hertz \\
\hline B3 & 246.853 \\
C4 & 261.376 \\
C\#4 & 276.958 \\
D4 & 293.958 \\
D\#4 & 311.314 \\
E4 & 329.728 \\
F4 & 349.562 \\
F\#4 & 370.46 \\
G4 & 392.416 \\
G\#4 & 415.794 \\
A4 & 440.582 \\
A\#4 & 466.79 \\
B4 & 494.773 \\
C5 & 524.165 \\
C\#5 & 555.332 \\
D5 & 587.915 \\
\hline
\end{tabular}

displayed in the information screen such as "user was added successfully", or "recording has been completed; to see the result click on 'results button." The frequencies of the sounds played are filed under the "recorded sound"

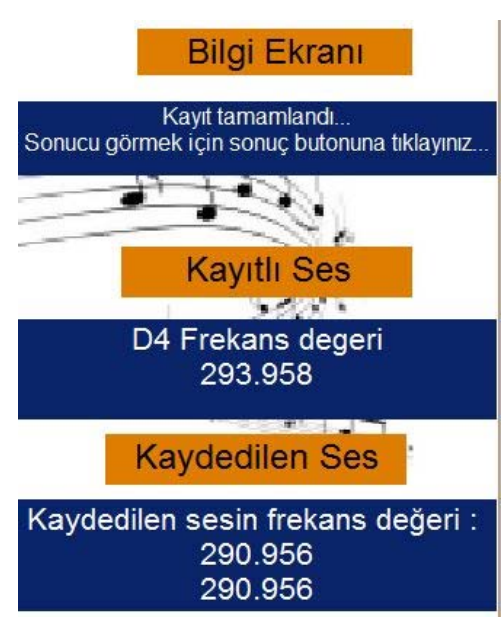

Figure 7. The Measurement results from P1 Points to D4 Note

\section{Bilgi Ekranı}

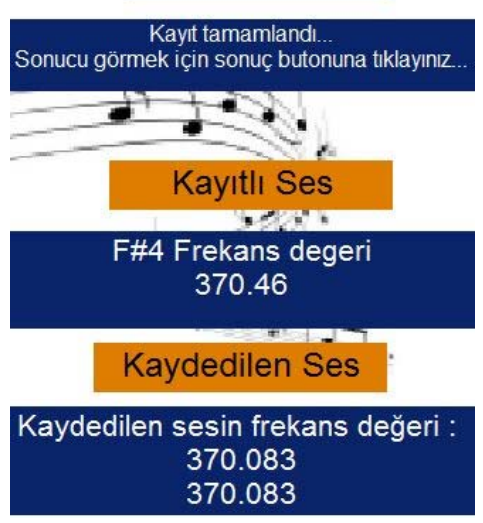

Figure 8. The measurement results from P1 Points to F\#4 Note.

section in the user interface. When the 'results button is clicked, frequency of the recorded sound is shown in "recorded sound" section by measuring the frequency of the recorded voice (Figure 6).

\section{Data obtained from the program}

The frequency of the notes between the ranges of B3-D5 used firstly in the program was measured again by the program. The measurement results obtained are listed in Table 1.

In the second stage of the study, the sounds have been reproduced using the program functions created with a microphone. Four screenshots obtained in this application are shown in Figures 7-10).

Tables 2-3 were created to compare the frequency 


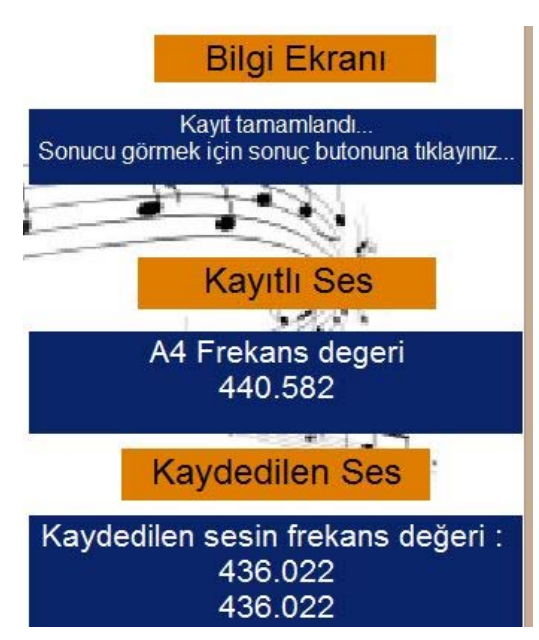

Figure 9. The measurement results from P1 Points to A4 Note

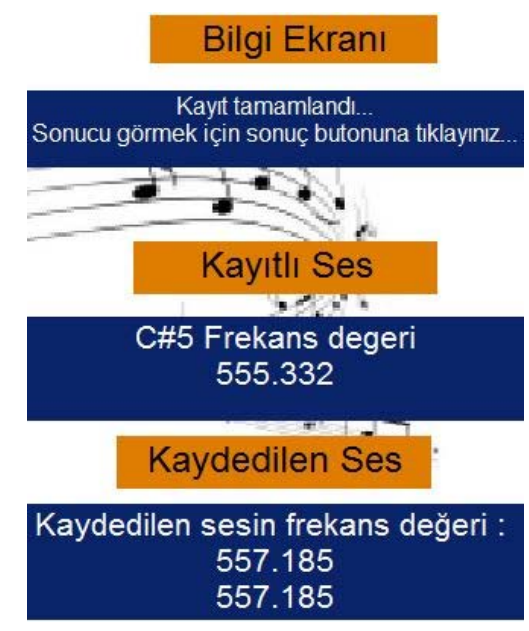

Figure 10. The measurement results from P1 Points to C\#5 Note

results obtained from measured sounds with those of already existing sounds.

Regarding the first test results of candidates, the differences between the existing sounds in the computer and the ones sung by candidates and resulting from the release of the human voice were observed, and these differences did not exceed 10 hertz.

In Table 1, interpreting the results of candidate P1, the difference between the frequency values does not exceed $5 \mathrm{~Hz}$. and the closest value is lower than $1 \mathrm{~Hz}$. This difference is due to the intensity of the vibrations caused by the human voice. Also, it is clear from the frequency comparisons in the table that the user who sought to imitate the sounds obtained a high rate of success. In broad sense, these differences are considered acceptable when they are within the range of -10 and +10 ; it has been established that even a 5-Hertzdifference did not exceed in near-far distance.

When the correlation results are analysed in Table 4, there is a positive and meaningful relationship between the fixed values of the frequencies of the notes between B3-D5 ( $\bar{X}=394.87$ ) and students' singing values ( $\bar{X}$ $=390.39$ ) at the end of this program application (Figure 11). Regarding this finding, it could be said that students closely replicated fixed frequency values and were very successful in program implementation.

Additionally, it appears students got very near to fixed frequency values and were very successful in the one voice exam, when we consider that the differences are between -10 or +10 hertz according to Pearson analysis results. Therefore, it seems reasonable to accept as correct those results which fall between -10 and +10 hertz of the exact pitch. Subsequent versions of the program will be developed accordingly.

\section{Graphics drawn by the program about B3-D5 notes \\ Graphics in the first step}

Figure 12 shows the frequency of the one voices used in the program. To draw the graphic, frequencies are taken from the notes between B3-D5 in the program's sound library with the function named as $t$. While drawing the graphic, the length of the frequency in seconds in $x$-axis, and width of it in (decibels) $d B$ in $y$-axis are shown.

\section{Graphics in the second step}

In Figure 13, using the graphic drawing feature of the program and the $t$ function mentioned above, magnitude values of the sound data are plotted along the $x$-axis to record the duration of the sound. The sound's magnitude in terms of $d B$ is displayed along the y-axis.

\section{Graphics in the third step}

In Figure 14, firstly, the Fourier Transform algorithm is implemented to calculate the absolute value of the frequencies and length of the sound files of existing B3D5 notes. The graphic of the related note is drawn by applying frequency $(\mathrm{Hz})$ to the $\mathrm{x}$-axis, and magnitude to the y-axis.

\section{Graphics obtained after the recorded voice in the fourth step}

In Figure 15, clicking the 'save' button generates the 
Table 2. The frequency values obtained from the Sounds by B3-D5 computer and P1-P5 candidates

\begin{tabular}{|c|c|c|c|c|c|c|}
\hline & PC & P1 & P2 & P3 & P4 & P5 \\
\hline Note & \multicolumn{6}{|c|}{ Frequency values $(\mathrm{Hz})$} \\
\hline B3 & 246,853 & 243,15 & 243,273 & 243,15 & 244,799 & 244,799 \\
\hline C4 & 261,376 & 262,108 & 260,459 & 263,344 & 255,514 & 256,338 \\
\hline C\#4 & 276,958 & 276,532 & 272,823 & 272,41 & 295,901 & 276,12 \\
\hline D4 & 293,958 & 290,956 & 286,423 & 290,544 & 295,077 & 289,719 \\
\hline D\#4 & 311,314 & 308,397 & 307,853 & 306,115 & 305,792 & 307,441 \\
\hline E4 & 329,728 & 327,222 & 316,095 & 320,628 & 325,574 & 323,513 \\
\hline $\mathrm{F} 4$ & 349,562 & 347,004 & 335,877 & 342,471 & 350,713 & 342,059 \\
\hline F\#4 & 370,46 & 370,083 & 364,346 & 360,302 & 365,549 & 359,78 \\
\hline G4 & 392,416 & 389,04 & 379,561 & 386,155 & 382,446 & 388,628 \\
\hline G\#4 & 415,794 & 412,531 & 406,349 & 410,882 & 409,234 & 410,849 \\
\hline A4 & 440,582 & 436,022 & 442,203 & 438,494 & 431,9 & 435,609 \\
\hline A\#4 & 466,79 & 466,931 & 465,282 & 458,276 & 449,209 & 463,221 \\
\hline B4 & 494,773 & 491,658 & 490,833 & 488,773 & 487,536 & 488,773 \\
\hline C5 & 524,165 & 520,506 & 519,682 & 519,27 & 515,148 & 523,803 \\
\hline C\#5 & 555,332 & 557,185 & 548,118 & 545,645 & 543,997 & 554,3 \\
\hline D5 & 587,915 & 588,093 & 582,324 & 589,742 & 583,148 & 583,56 \\
\hline
\end{tabular}

Table 3. Frequency levels of the sounds of the computer and P6-P10 candidates in B3-D5

\begin{tabular}{|c|c|c|c|c|c|c|}
\hline & PC & P6 & P7 & P8 & P9 & P10 \\
\hline Note & \multicolumn{6}{|c|}{ Frequency values $(\mathrm{Hz})$} \\
\hline B3 & 246,853 & 242,738 & 242,402 & 241,914 & 244,386 & 244,35 \\
\hline C4 & 261,376 & 257,574 & 253,865 & 260,047 & 256,75 & 255,30 \\
\hline C\#4 & 276,958 & 272,823 & 268,508 & 277,768 & 274,978 & 275,29 \\
\hline D4 & 293,958 & 289,719 & 284,774 & 292,604 & 295,077 & 295,20 \\
\hline D\#4 & 311,314 & 304,556 & 307,028 & 303,319 & 303,319 & 305,30 \\
\hline E4 & 329,728 & 321,865 & 322,689 & 322,277 & 322,689 & 328,05 \\
\hline F4 & 349,562 & 345,352 & 343,707 & 344,531 & 342,059 & 342,48 \\
\hline F\#4 & 370,46 & 365,549 & 366,786 & 365,961 & 361,428 & 383,68 \\
\hline G4 & 392,416 & 387,392 & 389,452 & 388,618 & 384,919 & 389,04 \\
\hline G\#4 & 415,794 & 415,004 & 410,882 & 407,998 & 411,707 & 420,13 \\
\hline A4 & 440,582 & 446,737 & 431,488 & 430,664 & 436,022 & 430,50 \\
\hline A\#4 & 466,79 & 464,046 & 459,512 & 460,337 & 463,634 & 465,45 \\
\hline B4 & 494,773 & 488,773 & 492,534 & 491,246 & 481,355 & 490,34 \\
\hline C5 & 524,165 & 520,918 & 525,451 & 513,088 & 518,445 & 520,45 \\
\hline C\#5 & 555,332 & 551,827 & 549,354 & 544,699 & 548,942 & 540,23 \\
\hline D5 & 587,915 & 582,736 & 584,384 & 581,912 & 588,093 & 590,65 \\
\hline
\end{tabular}

Table 4. Frequency levels of the sounds of the computer and P1-P10 candidates in B3-D5 the pearson test correlation analysis results

\begin{tabular}{lccccc}
\hline Score Type & $\mathbf{N}$ & $\bar{X}$ & sd & $\mathbf{r}$ & $\mathbf{p}$ \\
\hline Fixed Frequency Values & \multirow{2}{*}{10} & 394.87 & 108.05 & \multirow{2}{*}{$.99^{* *}$} & .00 \\
Student Frequency Values & & 390.39 & 107.55 & & \\
\hline${ }^{* *} \mathbf{p}<.01$. & & & & &
\end{tabular}




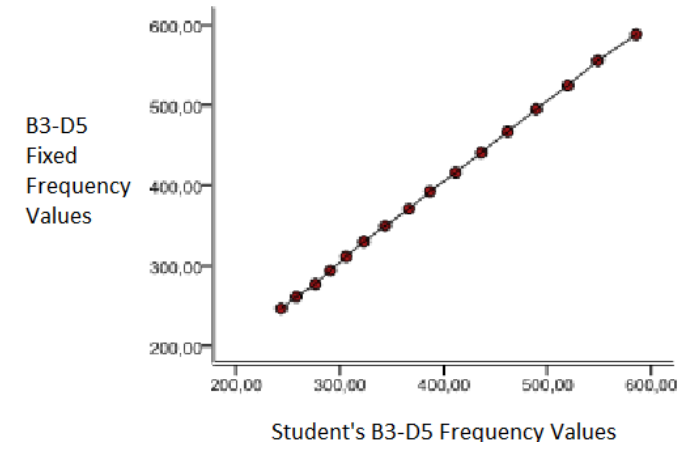

Figure 11. Students' B3-D5 frequency values
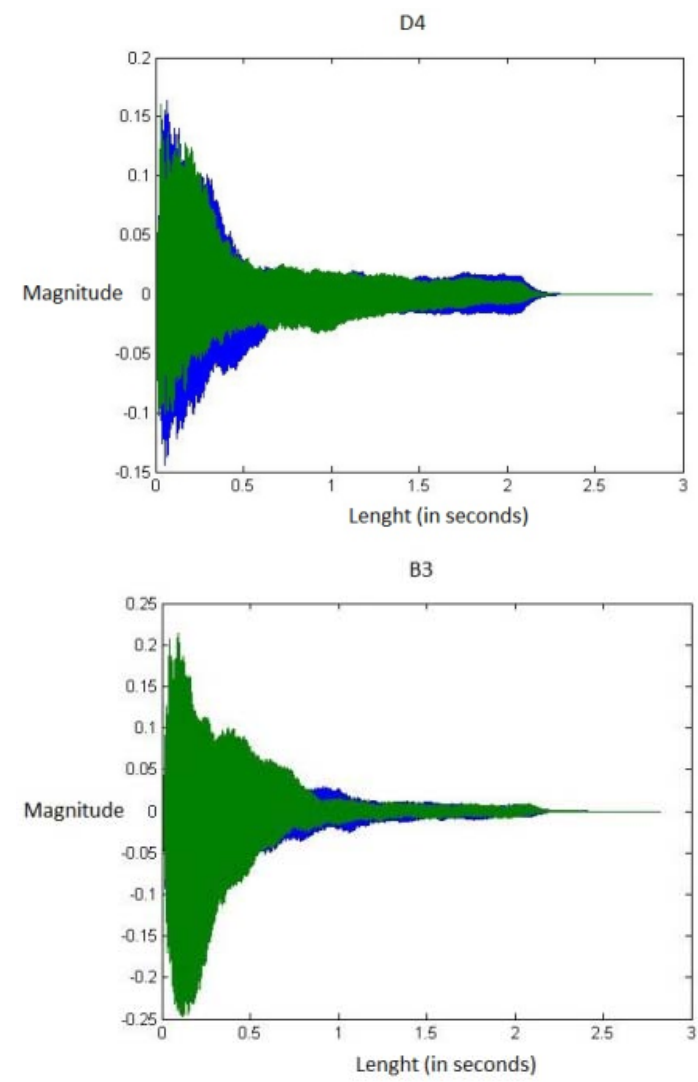

Figure 12. Frequency of the one voices used in the program.

graphic of the sound that has been recorded; in Figure 14, functions are being implemented. Thus, we get the chance to compare these two graphics. A few graphics from the P1 application are in Figure 15.

\section{Graphics obtained after the recorded voice in the fifth step}

Figure 16 shows frequency on the $x$-axis and magnitude
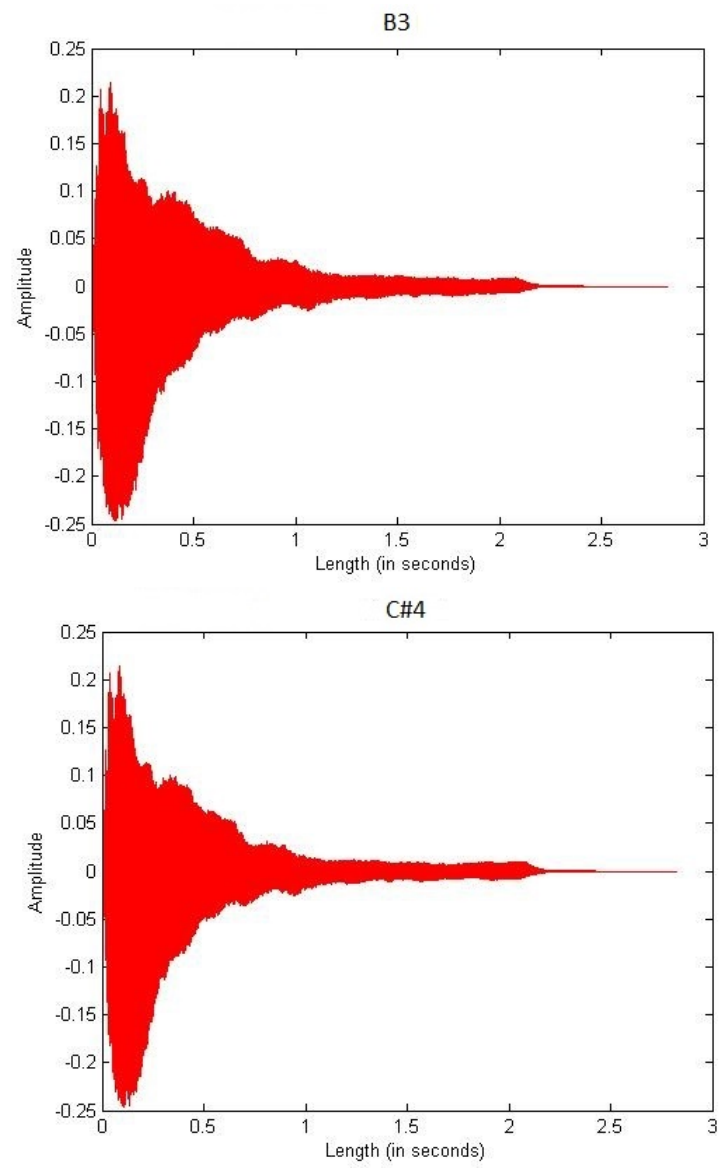

Figure 13. Magnitude values of the sound data.

on the $y$-axis by using the functions of the recorded sound in the program and commands written, and which generally shows its absolute value is obtained.

More detailed data and graphic displays are obtained by using the zoom in and out features in the program shown above in the third, fourth and fifth steps. In this study only some general information has been presented about these graphics.

\section{CONCLUSION AND SUGGESTIONS}

In accordance with the data obtained so far, it appears that measurement and assessment processes could easily be carried out with this software that has been prepared for single-note music talent exams. More importantly, reliable results are obtained. By analysing the graphics of the results, more detailed information is accessed.

The use of this program, which has been developed with codes in MATLAB program and especially the Fourier Transform algorithm, in music aptitude tests could prevent erroneous measurement situations, which occur 

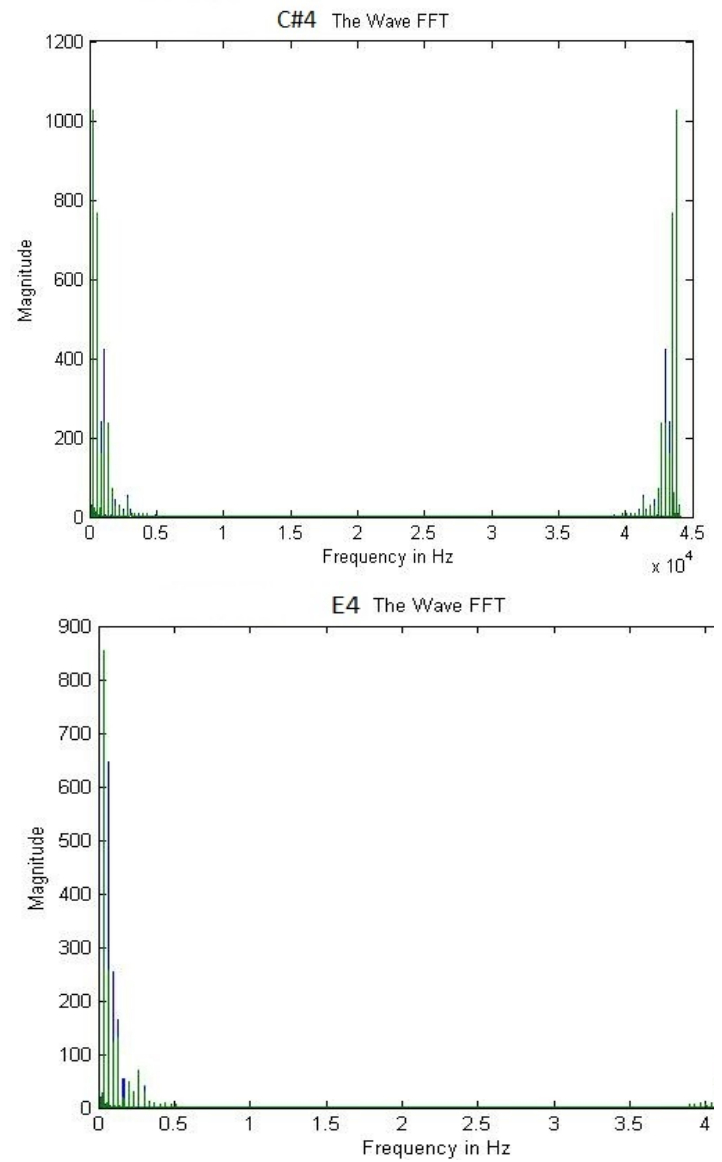

Figure 14. The absolute value of the frequencies and length of the sound files of existing B3-D5 notes.

due to reliance on hearing based on human perception. This is very important when considering educational aspects. It is a well-known fact that one of the main objectives of education is measurement and evaluation. It becomes much more important when it comes to the musical aptitude tests where candidates are chosen according to their level of aptitude knowledge. It is very important that the students taking these exams can put faith in the reliability of the tests, and in doing so minimize their nervousness.

Another aspect of the aptitude test is the excitement factor which affects the performance of the candidate. A program such as this could be applied to question types identifying intervals and chords of 2, 3 and 4 notes. Even so, the negative factors such as time and excitement could be reduced with an aptitude test measurement exam which includes repeating questions on the subjects of melody and rhythm. It would be fairly straightforward to incorporate these into the program by designing the necessary algorithms.

In many music aptitude tests problems result from the weakness of the evaluating jury, as well as the stress of
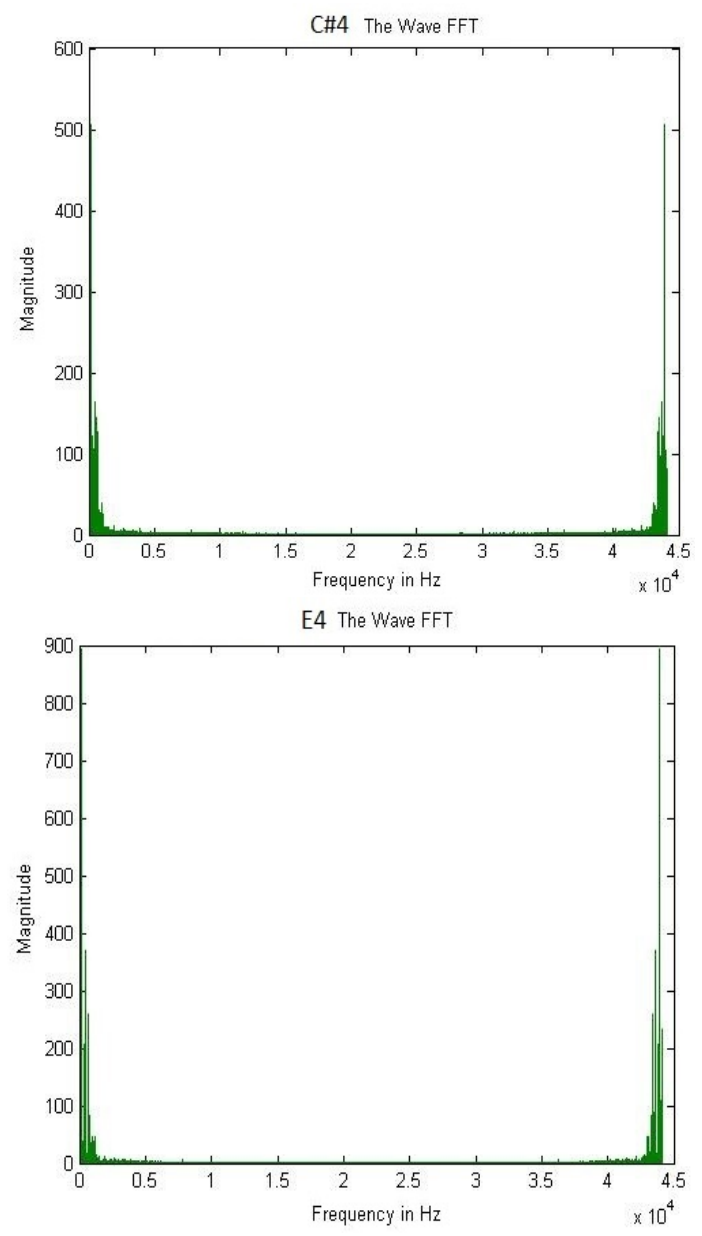

Figure 15. Recorded sound.

candidates who take the exams in short periods and in order. Sometimes, candidates may incorrectly sing the sound they hear due to excitement and tiredness after a prolonged wait. To avoid that, exams can be implemented individually in a more relaxed environment, using a lot of computers placed in special exam rooms equipped with security cameras. Candidates will be able to do their own exams whenever they are ready for the test.

Additionally, in measuring a definitive scoring will emerge. Such an exam, ranking the candidates by comparing their frequencies, is needed when it is considered in these aspects.

By developing the basic principles of the program's algorithm, a perfect measurement could be carried out in ear training exercises, by using these principles in twotone intervals, and basic situation and cycle of three or four chords.

Thus, the material errors encountered in the aptitude test results will be reduced to a minimum. Although it may seem difficult at first, this function can be constructed logically. When two, three or four loud voices are directed 

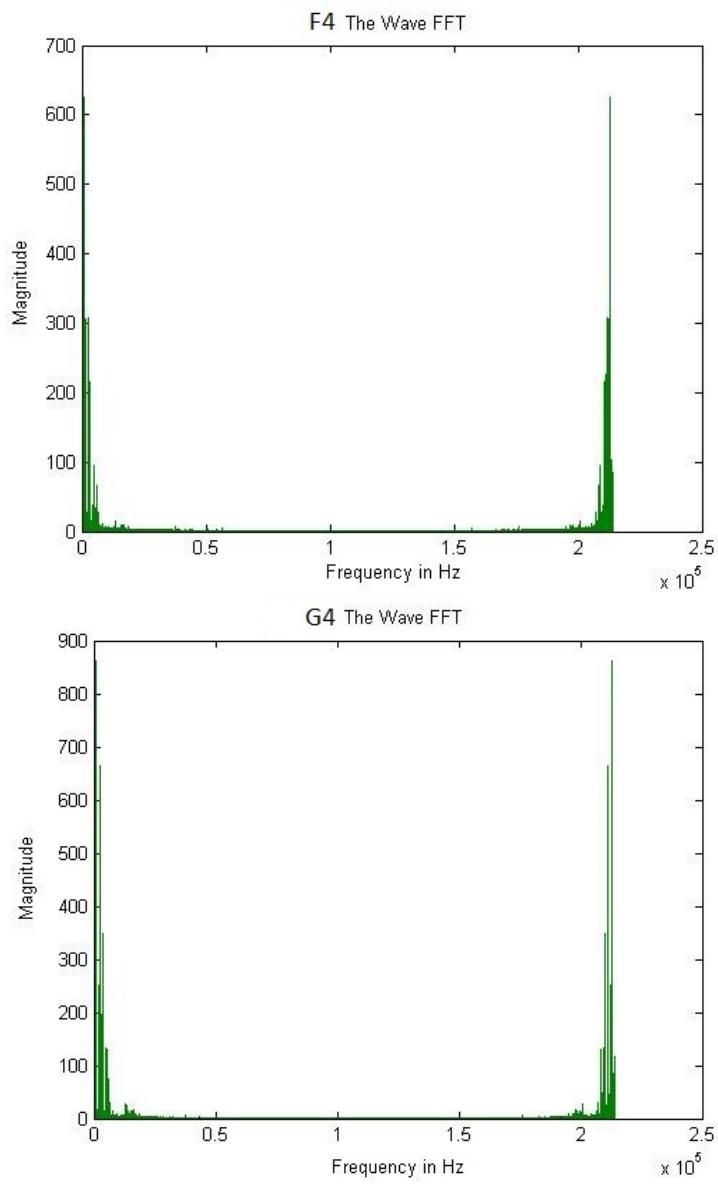

Figure 16. frequency of the x-axis and magnitude of the $y$-axis

to the person, she or he will give the sound one by one by decoupling them. To be able to measure the sounds given with certain time intervals and to record them with a microphone, by adding a few things to the algorithm which is used in measuring the one sound, it is possible to see the voice responses which are given to two, three or four voices, and the measured frequencies separately in the results section. In this way, the extent to which there is error or truth in implementations can be obtained more clearly and comprehensively, as it is applied to sounds other than a single voice.

In order to improve the usefulness of this study, in the results of the first measurement, it has been observed that there is a meaningful and positive relationship in the Pearson correlation test results $\left({ }^{* *} p<.01\right)$ of the musically talented students. Regarding this finding, it could be said that the students produced results significantly closer to fixed frequency values and became quite successful in the program implementation.

It seems essential to use this application in aptitude test by developing it in this sense. By developing the first version of the program, positive contributions to music education could be made with measurements at this level.

Regarding the possibilities for its use in different fields, this program could potentially be used in medical studies related to voice, such as determining which vocal chords give which frequency intervals. It could be used as a competitive music game, by giving sounds in approximate levels as in a musical intelligence game.

We can compare the sounds of piano and other instruments by using the 'save' button. For instruments other than piano, information about attitude and frequency of their characteristic sounds can be obtained by recording these instruments.

Such examples can be increased easily. MATLAB commands offer us these facilities. Also, it is understood that the "musical aptitude test" developed in MATLAB program runs according to the foreseen objectives. All the results of this program and its implementation results (on trained people in single sound) show us that the musical aptitude test developed with this program will overlap with the objectives of this study and will shed light on further studies by constituting the basis of them. With the development of the program a full-fledged Music Aptitude Test Application can be developed for worldwide use. Thus, the project underlying this study will contribute to the field of music.

\section{Conflict of Interests}

The author has not declared any conflict of interests.

\section{REFERENCES}

Alm JF, Walker JS (2002). Time-frequency analysis of musical instruments, SIAM Rev. 3(44):457-476.

Arapgirlioğlu H (2003). Music technology and music education in the new century, Music symposium at the 80th year of our republic, Inonu Univ. Malatya pp.160-164.

Bauer WI, Reese S, Peter A (2003) Transforming music teaching via technology: the role of professional development, McAllister source: J. Res. Music Educ. 4(51):289-301.

Başuğur ID (2009). Using interactive software in music education, 8th National Music Education Symposium, Ondokuz Mayıs Univ.

Havelock D, Kuwano S, Worlander M (2008). Handbook of signal processing in acoustics, Springer Science+Business Media, LLC, eISBN: 978-0-387-30441-0

Koç A (2004). The contributions of the computer based music software today to the music education, 1924-2004 from music teacher training schools to present declaration of music teacher training symposium, Süleyman Demirel Univ. Isparta.

Moorer JA (1977). Signal processing aspects of computer music, Comput. Music J. 1(1):4-37.

Naranjo M, Koffi A (1988). Geometric image modelling of the musical object, Leonardo. Supplemental Issue, Electronic Art (1):69-72.

Röbel A (2003). Frequency-Slope estimation and its application to parameter estimation for non-stationary sinusoids, Comput. Music J. 2(32):68-79. DOI: 10.1162/comj.2008.32.2.68

Rumsey F (2004). Desktop audio technology, Focal Press, ISBN: 0240 519191 
Sağer T, Zahal O, Gürpınar E, Özhan U (2014). The relations among OBP, field points and states of exam success in a special aptitude exam of music teaching programme, Int. J. Soc. Sci. (24):33-46, Doi number: http://dx.doi.org/10.9761/JASSS2240

Sağer T, Zahal O, Gürpınar E (2013). The examination of the relationship between YGS scores and music field scores in music teaching programme with special talent examination, Int. J. Human Sci. 10(1): 541-554.
Zeren A (2003). Physics of Music, Pan Publications, Istanbul.

Zeren A (2008). Sound Systems in Music, Pan Publications. Istanbul. 